\title{
The Faraday and British Association Centenaries.
}

THE Royal Institution, the Institution of Elec1 trical Engineers, and the British Association have recently issued programmes of the various events arranged in connexion with the Faraday centenary celebrations and the British Association centenary meetings, being held in London in September. From these, it will be seen that the Faraday centenary celebrations will begin with a reception of the delegates in the Royal Institution on Sept. 21 and conclude with the closing of the Faraday Exhibition on Oct. 3, while the meetings of the British Association will extend over the period Sept. 23-30.

The principal events of the Faraday celebrations will take place, with certain exceptions, on Sept. 21-23. At 11.30 A.M., Sept. 21, an informal meeting will be held in the lecture theatre of the Royal Institution, when an explanation of the programme will be given in English, French, and German, and at 3 P.M. the delegates to the celebrations will be received in the lecture theatre by the president and managers of the Institution. The Faraday commemorative meeting will be held that evening at 8 P.M., in Queen's Hall, Langham Place. W.1. Short speeches will be made by distinguished representatives of institutions in various parts of the world. Music will be given by the Symphony Orchestra of the British Broadcasting Corporation, under the direction of Sir Henry Wood, and the proceedings will be broadcast.

The proceedings of Sept. 22 will begin at 10.30 with a conference of the Institution of Electrical Engineers, to be held at Kingsway Hall, Kingsway, W.C.2. Speakers will include Mr. C. C. Paterson, (president), Mr. Ll. B. Atkinson, Miss C. Haslett, Mr. J. S. Highfield, Sir Oliver Lodge, and Sir Josiah Stamp, the subject for the conference being "The Place of Electricity in the Production and Utilization of Power, and in Transport, Communications, and the Household ". On that evening, at 8.30 , conversaziones will be held by both the Royal Institution and the Institution of Electrical Engineers, the conversazione of the latter taking place at the Albert Hall, thus enabling the guests to have a private view of the Faraday Exhibition.

The Faraday Exhibition has been organised by the Institution of Electrical Engineers, assisted by the Royal Institution, in regard to Faraday's original experiments, and by the Federal Council for Chemistry, in relation to chemical discoveries. It will be formally opened to the public at 4.30 on Sept. 23, and will remain open until the evening of Saturday, Oct. 3, the charge for admission being 1s. for adults and $6 d$. for children under fourteen. The exhibition is being planned to illustrate the developments of electrical and chemical science and industry in all branches which have followed Faraday's work. Around a statue of Faraday, in the centre of the hall, will be an exhibition of historic apparatus, and from this the exhibits will spread out radially, so that at the outer circumfer- ence of the hall will be found the latest examples of electrical apparatus and machinery. There will be nine sections in all, relating to such things as the generation, transmission, and distribution of electric power, electric transport, domestic uses of electricity, and the many branches of electric communication.

In the Albert Hall also, on Sept. 23, at 3 P.M., Lieut.-Gen. the Right Hon. J. C. Smuts will assume the presidency of the British Association, and will receive the invited delegates to the centenary meetings of the Association. At 4.30 P.M., at the invitation of the Institution of Electrical Engineers, he will open the Faraday Exhibition. These will be the inaugural proceedings of the British Association, and in the evening at 9 P.M., in the Central Hall, Westminster, General Smuts will deliver his presidential address.

In addition to these events, the Royal Institution has arranged for a garden party on Sept. 24, at the National Physical Laboratory, by the invitation of the director, Sir Joseph Petavel; and on the evening of Sept. 25, His Majesty's Government will entertain representative delegates and guests to dinner at the Dorchester Hotel, Park Lane. The Prime Minister, Mr. Ramsay Macdonald, hopes to preside. Various visits and excursions are being arranged, and the rooms of the Royal Institution will be at the disposal of delegates and guests from Sept. 12 until Sept. 26.

In connexion with the British Association meetings, a volume is being issued to members, entitled "London and the Advancement of Science", containing a historical survey of the advancement of science in London through the principal scientific, educational, and State institutions, etc., by various authors; together with another on "The British Association : a Retrospect, 1831-1931", by $\mathrm{Mr}$ O. J. R. Howarth. This is a revised edition of the volume issued in 1922 through the generosity of the late Sir Charles Parsons. It was in 1831, at York, that the Association held its first meeting, and York has been chosen for the meeting in 1932. But an invited party from the Association will pay a visit to its birthplace on Saturday and Sunday, Sept. 26-27, in the middle of the present meeting.

The publications from which these particulars have been taken contain much further information regarding the general arrangements, railway fares, hotel accommodation, passport visas, etc.

Attention may also be directed to a small pamphlet issued by the Metropolitan Borough of Southwark about the Faraday Memorial Library, which was opened in Southwark in 1927. Faraday was born at a house in Newington Butts in the borough, in 1791, and the library, which was established to commemorate his work, now contains some 1800 books devoted to the life and work of Faraday, with text-books and periodical publications of scientific societies. It is maintained by a small endowment fund in the hands of four trustees. 